\title{
ManeJo Químico das Plantas Daninhas Euphorbia heterophylla E Bidens pilosa Em Sistema de Plantio DiReto da Cultura DE SOJA ${ }^{1}$
}

\author{
Chemical Management of the Weeds Euphorbia heterophylla and Bidens pilosa under \\ No-Tillage System of Soybean (Glycine max)
}

CARVALHO, F.T. ${ }^{2}$, PEREIRA, F.A.R. ${ }^{3}$, PERUCHI, M.. e PALAZZO, R.R.B. ${ }^{4}$

\begin{abstract}
RESUMO - Objetivou-se neste trabalho avaliar a eficácia agronômica e os efeitos fitotóxicos de herbicidas aplicados em pré-plantio no manejo de Euphorbia heterophylla e Bidens pilosa, em sistema de plantio direto da cultura de soja. O experimento foi desenvolvido na safra 2000/2001, na FEP-UNESP, no município de Selvíria-MS. A variedade de soja utilizada foi a 'Conquista', e o delineamento experimental adotado foi o de blocos ao acaso, com sete tratamentos e quatro repetições, com oito linhas da cultura, totalizando $20 \mathrm{~m}^{2}$ cada parcela. Os tratamentos foram os seguintes: glyphosate $\left(720\right.$ e $\left.960 \mathrm{~g} \mathrm{ha}^{-1}\right)$, chlorimuron-ethyl + glyphosate $\left(10 \mathrm{~g}+720\right.$ e $\left.960 \mathrm{~g} \mathrm{ha}^{-1}\right)$, glyphosate +2 ,4-D $\left(960+868 \mathrm{~g} \mathrm{ha}^{-1}\right)$ e testemunhas no mato e no limpo. As aplicações foram realizadas com pulverizador de pressão constante $\left(\mathrm{CO}_{2}\right)$ de $45 \mathrm{lb} \mathrm{pol}^{-2}$, com barra equipada com quatro bicos do tipo leque Teejet $110.03 \mathrm{XR}$, espaçados de $0,5 \mathrm{~m}$, e volume de calda de $250 \mathrm{~L} \mathrm{ha}^{-1}$. Concluiu-se que os tratamentos testados são eficientes na dessecação de $E$. heterophylla e $B$. pilosae seletivos às plantas de soja. O herbicida chlorimuron-ethyl (10 $\left.\mathrm{g} \mathrm{ha}^{-1}\right)$ aplicado juntamente com o glyphosate, no manejo, proporciona ao tratamento um efeito residual significativo para E. heterophylla e $B$. pilosa, reduzindo a infestação das plantas daninhas durante o ciclo da cultura da soja.
\end{abstract}

Palavras-chave: herbicida, plantas daninhas, controle, residual, Glycine max, chlorimuron, glyphosate, 2,4-D.

\begin{abstract}
The objective of this work was to evaluate the agronomic efficacy and selectivity of the phytotoxic effects of post-emergent herbicides, applied in pre-planting, in the control of Euphorbia heterophylla and Bidens pilosa under no tillage system of soybean. The experiment was conducted during the growing season of the crop 2000/2001, in FEP-UNESP, in Selviria-MS, Brazil. The soybean variety used was 'Conquista', and the experimental design was a randomized block, with seven treatments, and four replications, with eight rows, totaling $20 \mathrm{~m}^{2}$, for each replication. The treatments were the following: glyphosate (720 and $\left.960 \mathrm{~g} \mathrm{ha}^{1}\right)$, chlorimuron-ethyl + glyphosate $\left(10 \mathrm{~g}+720\right.$ and $\left.960 \mathrm{~g} \mathrm{ha}^{-1}\right)$, glyphosate $+2,4-\mathrm{D}\left(960+868 \mathrm{~g} \mathrm{ha} \mathrm{h}^{-1}\right)$, and control with and without weeds. The applications were accomplished with a pulverizer of constant pressure $\left(\mathrm{CO}_{2}\right)$ of $45 \mathrm{lb} \mathrm{pol}^{-2}$, with a bar equipped with four beaks of the fan type Teejet $110.03 \mathrm{XR}, 0.5 \mathrm{~m}$ spaced and $250 \mathrm{~L} \mathrm{ha}{ }^{1}$ volume. It was observed that the treatments were efficient in the control of $\boldsymbol{E}$. heterophylla and $\boldsymbol{B}$. pilosa and are selective to the soybean plants. The herbicide chlorimuron-ethyl $\left(10 \mathrm{~g} \mathrm{ha}^{1}\right)$ applied together with the glyphosate, provides to the treatment a significant residual effect for $\boldsymbol{E}$. heterophyllaheterophylla and B. pilosa, reducing weed infestations during the soybean crop cycle.
\end{abstract}

Key words: herbicide, weeds, control, residual, Glycine max, chlorimuron, glyphosate, 2,4-D.

Recebido para publicação em 27.5.2002 e na forma revisada em 2.4.2003.

2 Prof. Dr., FEIS-UNESP, Av. Brasil, 56, Caixa Postal 31, 15385-000 Ilha Solteira-SP, <ftadeu@bio.feis.unesp.br>. ${ }^{3}$ Prof. Dr., UNIDERP, Campo Grande-MS. ${ }^{4}$ Graduandos de Agronomia da FEIS/UNESP. 


\section{INTRODUÇÃO}

As condições edafoclimáticas destacam o Brasil como país de grande potencial para o cultivo da soja. Entretanto, o clima tropical é também muito favorável à ocorrência de grande quantidade de plantas daninhas, que interferem no desenvolvimento e na produtividade das culturas. Os efeitos negativos detectados no crescimento e na produtividade da cultura da soja, decorrentes da presença das plantas daninhas, já foram observados por vários autores (Carvalho \& Durigan, 1995; Spadotto et al., 1994; Barros et al., 2000).

As perdas mundiais de produção de grãos de soja por ano, devido à interferência das plantas daninhas, são de 13\%; contudo, no clima tropical do Brasil, as perdas podem ser maiores (ASSOCIAÇÃO ... - ANDEF, 1987). Segundo Blanco (1985), as perdas de produção de soja em razão da concorrência com as plantas daninhas, no Brasil, podem variar de 42 a 95\%, e o período crítico de competição ocorre entre os 20 e 40 primeiros dias do ciclo da cultura.

Uma das tecnologias utilizadas na cultura da soja é o cultivo sem o revolvimento do solo. A prática do plantio direto tem como principal vantagem a conservação do solo. No entanto, um dos principais problemas detectados no sistema é a ocorrência de plantas daninhas e suas interações com o ambiente, prejudicando as plantas cultivadas.

Existem diferentes métodos para o controle das plantas daninhas. Na cultura da soja, o controle químico é o que tem sido mais utilizado, por vários motivos, entre eles devido às extensas áreas cultivadas. No plantio direto, o controle das invasoras depende da utilização de herbicidas, uma vez que os cultivos e as capinas são incompativeis com a tecnologia utilizada no sistema.

Os herbicidas utilizados no manejo das plantas daninhas antes da semeadura da cultura, para a formação da palhada, são muito importantes no plantio direto, com destaque para os dessecantes sem efeito residual, como o glyphosate e o paraquat.

A utilização de herbicidas no manejo que permite efeito residual no solo pode ser uma alternativa para reduzir a infestação de plantas daninhas na cultura implantada e, conseqüentemente, proporcionar economia nos custos de controle das plantas daninhas. A mistura de glyphosate com chlorimuron-ethyl tem se mostrado eficiente na dessecação das plantas daninhas e proporciona efeito residual significativo, reduzindo a infestação durante o ciclo da cultura (Carvalho et al., 2000; Carvalho \& Cavazzana, 2000; Valente \& Cavazzana, 2000).

O objetivo do trabalho foi avaliar a eficácia agronômica de herbicidas pós-emergentes no manejo de Euphorbia heterophylla e Bidens pilosa para o plantio direto de soja, bem como verificar os possiveis efeitos fitotóxicos dos tratamentos à cultura.

\section{MATERIAL E MÉTODOS}

O experimento foi desenvolvido em Latossolo Vermelho-Escuro textura argilosa, com $47 \%$ de argila, $33 \%$ de areia e $20 \%$ de silte, no período de dezembro/2000 a abril/2001, em área irrigada da Fazenda Experimental da FEIS-UNESP, localizada no município de Selvíria-MS, enquadrada em região de cerrado, no sudeste do Mato Grosso do Sul.

A variedade de soja utilizada foi a 'Conquista', semeada mecanicamente em 11.12.00, no espaçamento de $0,50 \mathrm{~m}$ entre linhas. A semeadura foi realizada sobre as plantas daninhas Euphorbia heterophylla e Bidens pilosa, presentes na área, no sistema "plantio direto sobre o mato". A emergência ocorreu em sete dias.

Os tratos culturais realizados na área experimental foram os normais exigidos pela cultura no que diz respeito às adubações e ao controle de pragas e doenças. No controle de doenças iniciais as sementes foram tratadas com o fungicida benomyl $(50 \mathrm{~g} / 100 \mathrm{~kg}$ de sementes). Antes da semeadura, realizou-se a inoculação das sementes, utilizando-se o produto Emerge PM à base de 20 gramas, diluídos em $600 \mathrm{ml}$ de água, para $80 \mathrm{~kg}$ de sementes. A adubação foi realizada concomitantemente à semeadura, utilizando-se a fórmula comercial 8-28-16 + 0,3\% de zinco à base de $250 \mathrm{~kg} \mathrm{ha}^{-1}$.

Foram realizadas duas aplicações de inseticida e fungicida, por época do florescimento e enchimento de grãos da cultura, para o controle de lagartas e percevejos e para prevenção de 
doenças. Os produtos utilizados foram o inseticida methamidophós (300 $\left.\mathrm{g} \mathrm{ha}^{-1}\right)$ e o fungicida benomyl (250 $\left.\mathrm{g} \mathrm{ha}^{-1}\right)$. As aplicações foram realizadas com um pulverizador de barra tratorizado e volume de calda de $200 \mathrm{~L} \mathrm{ha}^{-1}$.

Os herbicidas avaliados foram aplicados na operação de manejo em pós-emergência das plantas daninhas e pré-semeadura da cultura (dois dias antes da semeadura). No tratamento testemunha no limpo, a operação de manejo foi realizada mecanicamente, utilizando-se enxadas, aos 15 e 30 dias após a semeadura. Nos demais tratamentos não foi feito o controle das plantas daninhas em pós-emergência da cultura, já que um dos objetivos do trabalho era avaliar o efeito residual dos herbicidas aplicados na dessecação.

O delineamento experimental adotado foi o de blocos ao acaso, com sete tratamentos e quatro repetições. Cada parcela constou de oito linhas da cultura, com $5 \mathrm{~m}$ de comprimento e $4 \mathrm{~m}$ de largura.

As aplicações dos herbicidas foram feitas com pulverizador costal com pressão constante $\left(\mathrm{CO}_{2}\right)$ de $45 \mathrm{lb} \mathrm{pol}^{-2}$, provido de tanque com capacidade de dois litros (garrafas descartáveis), e com barra equipada com quatro bicos do tipo leque, marca Teejet $110.03 \mathrm{XR}$, espaçados de meio metro. O volume de calda aplicado foi de $250 \mathrm{~L} \mathrm{ha}^{-1}$.

As aplicações foram realizadas em pósemergência das plantas daninhas, no dia
9.12.00, das 19 às $19 \mathrm{~h} 45$, com o solo úmido, em decorrência de uma irrigação de $12 \mathrm{~mm}$ realizada quatro horas antes das aplicações. A temperatura do ambiente foi de $28{ }^{\circ} \mathrm{C}$, a umidade relativa do ar, de $75 \%$, e a velocidade do vento, inferior a $3 \mathrm{~km} \mathrm{~h}^{-1}$, durante as aplicações.

A eficiência dos herbicidas na dessecação das plantas daninhas foi avaliada aos 15, 30 e 45 dias após a aplicação (DAA) dos tratamentos (Tabelas 1 e 2). Foi utilizada uma escala visual em que $0 \%=$ nenhum controle e $100 \%=$ controle total das plantas daninhas. Considerouse como eficiente o controle superior a $80 \%$. Avaliou-se a infestação das plantas daninhas nas testemunhas sem capinas, aos 15, 30 e 45 DAA, através de notas de porcentagem de infestação (visual), e a reinfestação nos tratamentos (Tabela 3), por meio da contagem do número de plantas $/ \mathrm{m}^{2}$ (no centro da parcela) aos 60 DAA.

Com relação à seletividade, os dados não estão apresentados no trabalho, pois não foi observado nenhum tipo de toxicidade às plantas da cultura. A avaliação de produtividade (Tabela 4) foi realizada aos 120 dias após a semeadura (10.4.00), coletando-se os grãos da área útil, ou seja, os $2 \mathrm{~m}^{2}$ centrais de cada parcela.

\section{RESULTADOS E DISCUSSÃO}

A densidade de plantas daninhas na área experimental, antes da aplicação dos herbicidas,

Tabela 1 - Porcentagem média de dessecação de Euphorbia heterophylla em função do tratamento aplicado. FEP-Selvíria, MS $(00 / 01)$

\begin{tabular}{|c|c|c|c|c|}
\hline \multirow{2}{*}{ Tratamento } & \multirow{2}{*}{$\begin{array}{c}\text { Dose } \\
\left(\mathrm{g} \mathrm{ha}^{-1}\right)\end{array}$} & \multicolumn{3}{|c|}{ \% Dessecação - E. heterophylla } \\
\hline & & $15 \mathrm{DAA}$ & $30 \mathrm{DAA}$ & $45 \mathrm{DAA}$ \\
\hline 1- testemunha no mato & $\overline{---}$ & 0,0 & 0,0 & 0,0 \\
\hline 2- testemunha no limpo & --- & 100,0 & 100,0 & 100,0 \\
\hline 3- glyphosate ${ }^{1 /}$ & 720 & 47,5 & 72,5 & 85,0 \\
\hline 4- glyphosate & 960 & 76,3 & 77,5 & 87,5 \\
\hline 5- chlorimuron-ethyl ${ }^{2 /}+$ glyphosate & $10+720$ & 66,3 & 81,8 & 86,8 \\
\hline 6- chlorimuron-ethyl + glyphosate & $10+960$ & 86,0 & 87,5 & 92,5 \\
\hline 7- glyphosate $+2,4-\mathrm{D}^{3 /}$ & $960+868$ & 86,3 & 90,0 & 92,5 \\
\hline
\end{tabular}

$\left(\mathrm{g} \mathrm{ha}^{-1}\right)=$ gramas de ingrediente ativo por hectare.

DAA = dias após a aplicação dos herbicidas.

Obs.: foi utilizado óleo mineral Assist $(0,5 \% \mathrm{v} / \mathrm{v})$ em todos os tratamentos químicos.

${ }^{1} /$ glyphosate $=$ Gliphogan $480 \mathrm{CE} ; \stackrel{2}{2}$ chlorimuron-ethyl = Classic; $\stackrel{3}{2}$ 2,4-D = Capri. 
era de 25 plantas $\mathrm{m}^{-2}$ de Euphorbia heterophylla (amendoim-bravo) com 8 a 10 pares de folhas e de 18 plantas $\mathrm{m}^{-2}$ de Bidens pilosa (picãopreto) com 4 a 6 pares de folhas. Durante o experimento, a infestação média das plantas daninhas aos 15, 30 e 45 DAA, nas testemunhas sem capinas, foi de, respectivamente, 30 , 49 e 66 de E. heterophylla e de 20, 26 e 30 de B. pilosa.

Quanto à eficiência dos tratamentos na dessecação das plantas daninhas, da área experimental (Tabelas 1 e 2), observa-se que todos eles foram eficientes na dessecação de Euphorbia heterophylla e Bidens pilosa, proporcionando índices de controle superiores a $80 \%$, aos 45 DAA. Esses dados estão de acordo com Lorenzi et al. (2000). Os tratamentos glyphosate (720 e $\left.960 \mathrm{~g} \mathrm{ha}^{-1}\right)$ foram eficientes no controle das plantas daninhas, porém os niveis máximos de controle apenas foram observados aos 45 DAA. Os tratamentos chlorimuron-ethyl + glyphosate $(10 \mathrm{~g}+720 \mathrm{~g}$

Tabela 2 - Porcentagem média de dessecação de Bidens pilosa em função do tratamento aplicado. FEP-Selvíria, MS (00/01)

\begin{tabular}{|c|c|c|c|c|}
\hline \multirow{2}{*}{ Tratamento } & \multirow{2}{*}{$\frac{\text { Dose }}{\left(\mathrm{g} \mathrm{ha}^{-1}\right)}$} & \multicolumn{3}{|c|}{ \% Dessecação - Bidens pilosa } \\
\hline & & $15 \mathrm{DAA}$ & $30 \mathrm{DAA}$ & $45 \mathrm{DAA}$ \\
\hline 1- testemunha no mato & --- & 0,0 & 0,0 & 0,0 \\
\hline 2- testemunha no limpo & --- & 100,0 & 100,0 & 100,0 \\
\hline 3- glyphosate ${ }^{1 /}$ & 720 & 60,0 & 70,0 & 83,8 \\
\hline 4- glyphosate & 960 & 70,8 & 75,0 & 90,0 \\
\hline 5- chlorimuron-ethyl ${ }^{2 / 1}+$ glyphosate & $10+720$ & 83,0 & 90,5 & 93,8 \\
\hline 6- chlorimuron-ethyl + glyphosate & $10+960$ & 95,0 & 98,3 & 99,3 \\
\hline 7-glyphosate $+2,4-\mathrm{D}^{3 /}$ & $960+868$ & 77,5 & 85,0 & 91,3 \\
\hline
\end{tabular}

$\left(\mathrm{g} \mathrm{ha}^{-1}\right)=$ gramas de ingrediente ativo por hectare.

DAA $=$ dias após a aplicação dos herbicidas.

Obs.: foi utilizado óleo mineral Assist $(0,5 \% \mathrm{v} / \mathrm{v})$ em todos os tratamentos químicos.

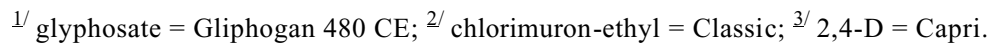

Tabela 3 - Reinfestação das plantas daninhas nos tratamentos testados. FEP-Selvíria, MS (00/01)

\begin{tabular}{|c|c|c|c|c|c|}
\hline \multirow[b]{2}{*}{ Tratamento } & \multirow{2}{*}{$\begin{array}{c}\text { Dose } \\
\left(\mathrm{g} \mathrm{ha}^{-1}\right)\end{array}$} & \multicolumn{2}{|c|}{ Euphorbia heterophylla } & \multicolumn{2}{|c|}{ Bidens pilosa } \\
\hline & & $\begin{array}{c}\text { Plantas m}^{-2} \\
(60 \text { DAA })\end{array}$ & $\begin{array}{c}\% \text { em relação à } \\
\text { testemunha }\end{array}$ & $\begin{array}{l}\text { Plantas }^{-2} \\
(60 \text { DAA) }\end{array}$ & $\begin{array}{l}\text { \% em relação à } \\
\text { testemunha }\end{array}$ \\
\hline 1- testemunha no mato & --- & $30,3 \quad \mathrm{a}$ & 100,0 & $25,5 \quad \mathrm{a}$ & 100,0 \\
\hline 2- testemunha no limpo & --- & $0,0 \mathrm{~d}$ & 0,0 & $0,0 \mathrm{c}$ & 0,0 \\
\hline 3- glyphosate ${ }^{-1}$ & 720 & $20,8 \mathrm{~b}$ & 68,6 & $20,8 \mathrm{ab}$ & 81,6 \\
\hline 4- glyphosate & 960 & $19,5 \mathrm{~b}$ & 64,4 & $18,0 \mathrm{ab}$ & 70,6 \\
\hline 5- chlorimuron-ethyl ${ }^{2}+$ glyphosate & $10+720$ & $9,0 \mathrm{c}$ & 29,7 & $1,0 \mathrm{c}$ & 3,9 \\
\hline 6- chlorimuron-ethyl + glyphosate & $10+960$ & $9,0 \quad \mathrm{c}$ & 29,7 & $0,5 \mathrm{c}$ & 2,0 \\
\hline 7- glyphosate $+2,4-D^{3}$ & $960+868$ & $10,8 \mathrm{c}$ & 35,6 & $8,8 \mathrm{c}$ & 34,5 \\
\hline \multicolumn{2}{|c|}{ Coeficiente de Variação (\%) } & 20,86 & -- & 56,10 & -- \\
\hline \multicolumn{2}{|l|}{ DMS (5\%) } & 6,91 & -- & 13,90 & -- \\
\hline
\end{tabular}

$\left(\mathrm{g} \mathrm{ha}^{-1}\right)=$ gramas de ingrediente ativo por hectare.

DAA $=$ dias após a aplicação dos herbicidas.

Obs.: foi utilizado óleo mineral Assist $(0,5 \% \mathrm{v} / \mathrm{v})$ em todos os tratamentos químicos.

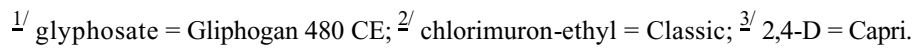

Médias seguidas de letras iguais, nas colunas, não diferem entre si a 5\% pelo teste de Tukey. 
e $10 \mathrm{~g}+960 \mathrm{~g} \mathrm{ha}^{-1}$ ) foram eficientes no controle de E. heterophylla e B. pilosa, proporcionando controle acima de 86 e $93 \%$, respectivamente, aos 45 DAA. O tratamento glyphosate +2 , 4-D $\left(960 \mathrm{~g}+868 \mathrm{~g} \mathrm{ha}^{-1}\right)$ foi eficiente no controle das plantas daninhas, proporcionando niveis médios de controle superiores a $91 \%$, aos 45 DAA.

Os dados de reinfestação das plantas daninhas (Tabela 3) confirmam o efeito residual dos herbicidas no controle das plantas daninhas. A reinfestação, aos 60 DAA, de E. heterophylla nos tratamentos com $10 \mathrm{~g} \mathrm{ha}^{-1}$ de chlorimuronethyl foi menor que $30 \%$, em relação à testemunha no mato, enquanto nos tratamentos com glyphosate isolado ela foi maior que $64 \%$. Esses dados demonstram a ocorrência de efeito residual do chlorimuron-ethyl, proporcionando o controle das plantas daninhas ao longo do tempo. Para B. pilosa esse efeito foi ainda mais pronunciado. Observa-se que a reinfestação da planta daninha aos 60 DAA foi menor que 4\% nos tratamentos com chlorimuron-ethyl, em relação à testemunha no mato, enquanto nos tratamentos com glyphosate isolado ela foi maior que $70 \%$.

Esse tipo de controle residual, conseguido na operação de manejo, é bastante interessante, pois, além de reduzir a competição das

Tabela 4 - Produtividade média da cultura em função do tratamento aplicado. FEP-Selvíria, MS (00/01)

\begin{tabular}{|c|c|c|}
\hline \multirow{2}{*}{ Tratamento } & Dose & \multirow{2}{*}{$\begin{array}{c}\text { Produtividade } \\
\left(\mathrm{kg} \mathrm{ha}^{-1}\right)\end{array}$} \\
\hline & $\left(\mathrm{g} \mathrm{ha}^{-1}\right)$ & \\
\hline 1- testemunha no mato & --- & $755,03 \quad \mathrm{c}$ \\
\hline 2- testemunha no limpo & --- & $2.319,90 \quad \mathrm{a}$ \\
\hline 3- glyphosate ${ }^{1 /}$ & 720 & $1.733,63 \mathrm{~b}$ \\
\hline 4- glyphosate & 960 & $1.772,25 \mathrm{~b}$ \\
\hline 5- chlorimuron-ethyl ${ }^{2 /}+$ glyphosate & $10+720$ & $2.125,83 \mathrm{ab}$ \\
\hline 6- chlorimuron-ethyl + glyphosate & $10+960$ & $2.293,98 \mathrm{a}$ \\
\hline 7- glyphosate $+2,4-\mathrm{D}^{3 /}$ & $960+868$ & $2.007,80 \mathrm{ab}$ \\
\hline Coeficiente de Variação (\%) & & 9,65 \\
\hline DMS (5\%) & & 418,61 \\
\hline
\end{tabular}

$\left(\mathrm{g} \mathrm{ha}^{-1}\right)=$ gramas de ingrediente ativo por hectare.

DAA $=$ dias após a aplicação dos herbicidas

Obs.: foi utilizado óleo mineral Assist $(0,5 \% \mathrm{v} / \mathrm{v})$ em todos os tratamentos químicos.

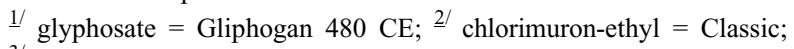

3/ $2,4-\mathrm{D}=$ Capri.

Médias seguidas de letras iguais, nas colunas, não diferem entre si a $5 \%$ pelo teste de Tukey. plantas daninhas no período crítico da cultura, facilita o controle pós-emergente, que pode ser realizado com doses minimas de herbicidas recomendados. Resultados semelhantes, obtidos com o herbicida chlorimuron-ethyl, foram relatados por Carvalho et al. (2000) para a espécie $E$. heterophylla; Valente \& Ornelas (2000), Carvalho \& Cavazzana (2000) e Valente \& Cavazzana (2000) para a espécie B. pilosa; e por Bizzi \& Bianchi (2000) para as espécies B. pilosa, Xanthium strumarium e Sida rhombifolia.

A estratégia de utilizar herbicidas no manejo que, além de aumentarem o espectro de controle do glyphosate, proporcionam efeito residual para o controle das plantas daninhas já é amplamente utilizada há algum tempo com o herbicida 2,4-D. Rossetto et al. (2000) mostraram os benefícios desse tipo de aplicação em sete ensaios realizados na safra 1999/2000. No entanto, a utilização do herbicida 2,4-D no manejo para o plantio direto da soja possui algumas restrições, como a necessidade de se esperar, no mínimo, 10 dias entre a aplicação e a semeadura (segundo Rodrigues \& Almeida, 1998) e a possibilidade de ocorrência de danos à cultura quando há pouca umidade no solo.

A possibilidade de se realizar a semeadura logo após a operação de manejo, utilizando-se herbicidas seletivos, possui a vantagem de explorar ao máximo o efeito residual dos herbicidas e, conseqüentemente, melhorar as condições para a cultura fechar no limpo. Essa condição é conhecida como "dianteira competitiva" e foi explorada pelos tratamentos utilizados no presente trabalho.

Os dados de produtividade (Tabela 4) confirmam os efeitos prejudiciais da competição entre cultura e plantas daninhas, já constatados por outros autores (Blanco et al., 1973, 1978; Spadotto et al., 1994; Barros et al., 1992, 2000; Carvalho, 2000). A convivência com as plantas daninhas prejudicou significativamente a produtividade da cultura no tratamento testemunha no mato.

\section{LITERATURA CITADA}

ASSOCIAÇÃO NACIONAL DE DEFENSIVOS AGRÍCOLAS - ANDEF. Defesa vegetal. São Paulo, SP: ANDEF, 1987. $19 \mathrm{p}$.

Planta Daninha, Viçosa-MG, v.20, n.1, p.145-150, 2002 
BARROS, A.C. et al. Avaliação de herbicidas no controle de plantas daninhas na cultura da soja. Planta Daninha, v. 10, n. 1/2, p. 45-49, 1992.

BARROS, A. C.; UEDA, A.; SCHUMM, K. C. Eficiência e seletividade do lactofen em mistura com outros latifolicidas, no controle de plantas daninhas na cultura da soja. Revista Brasileira de Herbicidas, v. 1, n. 1, p. 79-84, 2000.

BIZZI, A. F.; BIANCHI, M. A. Eficácia da mistura de chlorimuron-ethyl com glyphosate na dessecação e residual sobre plantas daninhas na soja. In: CONGRESSO BRASILEIRO DA CIÊNCIA DAS PLANTAS DANINHAS, 22., 2000, Foz do Iguaçu-PR. Resumos... Londrina: SBCPD, 2000. p. 118

BLANCO, H. G. et al. Observações sobre o período em que as plantas daninhas competem com a soja [Glycine $\max (\mathrm{L}$.) Merrill]. O Biológico, v. 39, n. 2, p. 31-35, 1973.

BLANCO, H. G.; OLIVEIRA, D. A.; ARAÚJO, J. B. M. Período crítico de competição de uma comunidade natural de mato em soja [Glycine max (L.) Merrill]. In: SEMINÁRIO NACIONAL DE PESQUISA DE SOJA, 1., 1978, Londrina. Anais... Londrina: EMBRAPA-CNPSO, 1978. p. 151-157.

BLANCO, H. G. Ecologia das plantas daninhas competição de plantas daninhas em culturas brasileiras. In: BLANCO, H. G. Controle integrado de plantas daninhas. 2.ed. São Paulo: CREA, 1985. p. 42-75.

CARVALHO, F. T.; CAVAZZANA, M. A. Eficácia de herbicidas no manejo de plantas daninhas para o plantio direto de soja. R. Bras. Herb., v. 1, n. 2, p. 167-172, 2000.

CARVALHO, F. T.; DURIGAN, J. C. Integração de práticas culturais e redução da dose de bentazon na cultura da soja. Planta Daninha, v. 13, n. 1, p. 46-49, 1995.
CARVALHO, F. T. et al. Eficácia de herbicidas no manejo de Euphorbia heterophylla para o plantio direto de soja. R. Brasil. Herb., v. 1, n. 2, p. 159-166, 2000.

LORENZI, H. et al. Manual de identificação e controle de plantas daninhas: plantio ditreto e convencional. 5.ed. Nova Odessa: Plantarum, 2000. 339 p.

RODRIGUES, B. N.; ALMEIDA, F. S. Guia de herbicidas. 4.ed. Londrina: Edição dos Autores, 1998. $648 \mathrm{p}$.

ROSSETO, J. et al. Avaliação de herbicidas alternativos ao uso de 2,4-D associados à glyphosate na dessecação de áreas de pousio. In: CONGRESSO BRASILEIRO DA CIÊNCIA DAS PLANTAS DANINHAS, 22., 2000, Foz do Iguaçu-PR. Resumos... Londrina: SBCPD, 2000. p. 116.

SPADOTTO, C. A. et al. Determinação do período crítico para prevenção da interferência de plantas daninhas na cultura da soja: uso do modelo "broken-stick". Planta Daninha, v. 12, n. 2, p. 59-62, 1994.

VALENTE, T. O.; ORNELAS, A. Efeito residual de chlorimuron-ethyl aplicado em mistura com glyphosate na dessecação em condições de cerrado. In: CONGRESSO BRASILEIRO DA CIÊNCIA DAS PLANTAS DANINHAS, 22., 2000, Foz do Iguaçu-PR. Resumos... Londrina: SBCPD, 2000. p. 117.

VALENTE, T. O.; CAVAZZANA, M. A. Efeito residual do chlorimuron-ethyl aplicado em mistura com glyphosate na dessecação de plantas daninhas. R. Bras. Herb., v. 1, n. 2, p. $173-178,2000$. 